\title{
Vocal Response of Captive-reared Saguinus oedipus During Mobbing
}

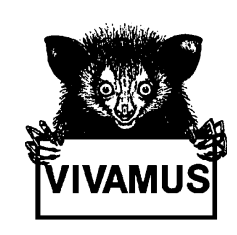

\section{Matthew W. Campbell • Charles T. Snowdon}

Published online: 30 May 2007

(C) Springer Science + Business Media, LLC 2007

\section{Erratum to: Int J Primatol \\ DOI 10.1007/s10764-007-9123-y}

The following errors were published in this paper because the vendor did not make these changes as indicated by the author. We apologize for these mistakes.

\section{Introduction}

I 1, line 3: Change "That" to "The"

ๆ 3, last sentence: Change "that controls do not" to "that are not given in control sessions"

\section{Methods}

Equipment and Procedure

I 3, lines 3-4: Change "and waved about the blue duster" to "and the experimenter waved about the blue duster". Explanation: the human in veterinary garb did not have the duster; these were two separate stimuli introduced independently of each other.

The online version of the original article can be found at http://dx.doi.org/10.1007/s10764-007-9123-y.

M. W. Campbell $(\bowtie) \cdot$ C. T. Snowdon

Department of Psychology, University of Wisconsin-Madison,

1202 W. Johnson St., Madison, Wisconsin 53706, USA

e-mail: mwcampbell@wisc.edu 
Data Analysis

ๆ 2, line 4: Change "corted" to "sorted"

\section{Results}

Overall Session Characteristics

Fig. 3 caption: Change "3 inflection points" to "2 inflection points"

\section{Discussion}

I 1, line 3: Change "response and have" to "response, and these calls have"

ๆ 2, line 4: Delete repeated occurrence of "continued" in the sentence 